\title{
La trehalosa: ¿una nueva panacea?
}

\section{Trehalose, a new panacea?}

\author{
Lorena C. Torres-Acosta*, Stephanie M. García-Alarcón y Luisa E. Mayta-Pitman
}

Instituto Nacional de Oftalmología, Lima, Perú

Señor Editor:

Hemos mostrado interés por el artículo Efecto de la trehalosa tópica al $3 \%$ en la velocidad de epitelización corneal en pacientes operados de queratectomía fotorrefractiva ${ }^{1}$, el cual consideramos una investigación interesante por estar relacionada con las alteraciones de la superficie ocular, un evento adverso muy frecuente tras cirugías refractivas, que genera un gran disconfort en el paciente y un círculo vicioso difícil de abordar.

La trehalosa actúa como una enzima con actividad en los proteoglicanos que intervienen en la cicatrización. Luego de la administración de trehalosa tópica, se vio la capacidad de proteger las estructuras proteicas y contribuir a la organización y la reepitelización del tejido, gracias al sistema ubiquitina-proteosoma y el aclaramiento autofágico lisosomal, que se activan para reparar las proteínas dañadas. Así mismo, se ha encontrado un incremento de la expresión de P62, un receptor de autofagia que aumenta la expresión de los factores antioxidantes y reduce la cantidad de radicales libres, previniendo así el daño celular ${ }^{2}$. La combinación de hialuronato de sodio con trehalosa en gotas oftálmicas ha demostrado una gran efectividad en la reepitelización corneal en intervenciones como LASIK (laser-assisted in situ keratomileusis) y
PRK (photorefractive keratectomy), en comparación con el uso de solo hialuronato, al reducir el número de células muertas en la superficie ocular mediante la supresión de la apoptosis ${ }^{3}$.

En el estudio realizado por Haber, et al. ${ }^{1}$ se evidenció que no aumentó la velocidad de epitelización corneal luego de la administración de trehalosa tópica, a diferencia del trabajo realizado por Aragona, et al. ${ }^{4}$, quienes concluyen que el uso de dicho fármaco sí contribuía en la reepitelización corneal. Probablemente esto se deba a que, en el estudio en mención, utilizaron parámetros más específicos para explicar la reepitelización corneal, como análisis morfométricos que determinaban el porcentaje de células vitales, el número de capas epiteliales, el grosor epitelial, el área de células basales, la densidad óptica del citoplasma e imágenes tomográficas, contribuyendo de esta manera a la obtención de datos más consistentes.

Por lo antes descrito, consideramos que el estudio de Haber, et al. ${ }^{1}$ pudo verificar su hipótesis; sin embargo, son necesarias pruebas más específicas que logren explicar con mayor detalle el proceso de reepitelización corneal.

Finalmente, tomando en consideración las distintas realidades en las cuales se pueden llevar a cabo 
dichos ensayos, quedaría pendiente el compromiso de seguir buscando pruebas de bajo costo para el seguimiento de la reepitelización corneal.

\section{Conflicto de intereses}

Los autores declaran que no presentan conflictos de intereses.

\section{Bibliografía}

1. Haber A., Polania-Barón EJ. Efecto de la trehalosa tópica al $3 \%$ en la velocidad de epitelización corneal en pacientes operados de queratectomía fotorrefractiva. Rev Mex Oftalmol. 2021;95:71-5.

2. Luyckx J, Baudouin C. Trehalose: an intriguing disaccharide with potential for medical application in ophthalmology. Clin Ophthalmol. 2011; 5:577-81.

3. Laihia J, Kaarniranta K. Trehalose for ocular surface health. Biomolecules. 2020;10:809.

4. Aragona P, Colosi P, Rania L, Colosi F, Pisani A, Puzzolo D, et al. Protective effects of trehalose on the corneal epithelial cells. Sci World J. 2014;2014:717835. 